\title{
Survivin and Telomerase as Radiotherapeutic Response Predictors of Subjects with Stage IIIB Cervical Squamous Cell Carcinoma
}

\author{
Fitriyadi Kusuma ${ }^{1}$, Andrijono ${ }^{1}$, Ani Retno Prijanti², Laila Nuranna ${ }^{1}$, Sri Mutya Sekarutami ${ }^{3}$, \\ Bambang Sutrisna ${ }^{4}$, Ferry Sandra ${ }^{5, *}$

\begin{abstract}
${ }^{1}$ Department of Obstetrics and Gynecology, Faculty of Medicine, Universitas Indonesia, J1. Salemba Raya No. 6, Jakarta 10430, Indonesia ${ }^{2}$ Department of Biochemistry and Molecular Biology, Faculty of Medicine, Universitas Indonesia, Jl. Salemba Raya No. 6, Jakarta 10430, Indonesia ${ }^{3}$ Department of Radiotherapy, Faculty of Medicine, Universitas Indonesia, Jl. Salemba Raya No. 6, Jakarta 10430, Indonesia ${ }_{5}^{5}$ Department of Biochemistry and Molecular Biology, Division of Oral Biology, Faculty of Dentistry, Universitas Trisakti, J1. Kyai Tapa No.260, Jakarta, Indonesia
\end{abstract} \\ ${ }^{4}$ Department of Epidemiology, Faculty of Public Health, Universitas Indonesia, Jl. Lingkar Kampus Raya Universitas Indonesia, Depok 16424, Indonesia \\ ${ }^{*}$ Corresponding author. E-mail: ferry@trisakti.ac.id
}

Received date: Apr 24, 2019; Revised date: Oct 3, 2019; Accepted date: Oct 31, 2019

\section{Abstract}

B ACKGROUND: Cervical cancer is one of the most prevalent cancers in women. Even with similar clinicopathologic features, radiotherapy outcomes are still vary among patients. This research was conducted to measure radiotherapy responses on cervical cancer patients by using Survivin, Telomerase and Cytochrome C.

METHODS: Subjects who matched the criteria were selected and requested to fill questionnaires. Subjects were then evaluated with magnetic resonance imaging (MRI) pre- and post-3D conformal radiotherapy. Histopathological study was conducted using resected tumors to determine the differentiation type. Enzyme-linked Immunosorbent Assays for detection of Survivin, Telomerase and Cytochrome C was performed using the resected tumors as well.

RESULTS: There were 76 patients in this study. Mean of age was 50 and diameter of tumor size was $5.35 \mathrm{~cm}$. Mean levels of Survivin, Telomerase and Cytochrome $\mathrm{C}$ were
$632.82 \mathrm{pg} / \mathrm{mL}, 5.59 \mathrm{pg} / \mathrm{mL}$ and $204.75 \mathrm{ng} / \mathrm{mL}$, respectively. There were significant correlations between radiotherapy response and Survivin $(p=0.041)$ or Telomerase $(p=0.022)$. Subjects with lower Survivin level $(<932 \mathrm{pg} / \mathrm{mL})$ had higher 1-year survival rate $(63 \%)$ than subjects with higher Survivin level $(50 \%)$. Similar results were obtained for subjects with lower Telomerase level $(<5.75 \mathrm{pg} / \mathrm{mL})$, who had higher 1-year survival rate $(60 \%)$ than subjects with higher Telomerase level (43\%).

CONCLUSION: Since radiotherapy response is significantly correlated with Survivin and Telomerase levels and subjects with lower Survivin or Telomerase level have higher 1-year survival rate, it can be suggested that Survivin and Telomerase could be potential predictors of radiotherapeutic response for subjects with stage IIIB cervical squamous cell carcinoma.

KEYWORDS: cervical cancer, radiotherapy Survivin, Telomerase, Cytochrome C

Indones Biomed J. 2020; 12(1): 27-33

\section{Introduction}

Cervical cancer is one of the most common cancers in women. Human Papilloma Virus (HPV) is closely related to the occurrence of cervical cancer.(1-4) The incidence of cervical cancer in Indonesia is 100 among 100.000 women. The mortality rate of patients with cervical cancer is still high
(90\%), since the patients seek for help in the advanced stage of disease.(5) Nearly $70 \%$ of patients with cervical cancer in Dr. Cipto Mangunkusumo Hospital Jakarta were in the stage of IIB to IVB. Therefore, the outcome of treatments were still far from satisfaction.(6) Radiotherapy and palliative chemotherapy are the treatments of choice for cervical cancer stage IIB to IVB.(7-9) However, there are failures in radiotherapy, $10 \%$ at stage $\mathrm{IIB}, 42 \%$ at stage III and $74 \%$ at 
stage IVA.(10) Success in cervical cancer therapy depends on clinicopathologic features, such as the cancer stage, tumor size, histopathological type, differentiation level and lymphocyte reaction.(5) However, radiotherapy outcomes in similar clinicopathologic features are not always alike.

Various tumor markers were studied to determine prognostic factor, such as serum associated antigen, angiogenic factor and apoptotic factor. Angiogenic factor was reported to have a role in early stadium, meanwhile apoptotic factor in both early and late stadiums.(11,12) Therefore, apoptotic factor such as Cytochrome $\mathrm{C}$ is important to be investigated. Cytochrome $\mathrm{C}$, which is produced by mitochondria, comprises 104 amino acids and plays an important role in cellular development or death. (13) Cytochrome C plays a role in the intrinsic pathway type 2 via the mitochondrial electron transport system. The role of Cytochrome $\mathrm{C}$ has been reported in various humans cancers, including thyroid (14), lung (15), colon (16), prostate (17), breast $(18,19)$, ameloblastoma (20), ovarian (21) and cervical cancers $(22,23)$.

Despite Cytochrome C, Survivin also plays an important role in the apoptotic pathway. Survivin is a member of the inhibitor of apoptosis (IAP) gene family, comprises 142 amino acids. Survivin has the capability to control cell proliferation and apoptosis.(24,25) Level of Survivin is very low in healthy tissue, but it is increasing in tumor tissue. $(24,26)$ Survivin overexpression is currently used as prognostic factor in the brain (27), breast (28), rectal (29) and bladder (30) cancers. In addition, level of Survivin has been used as a predictor for treatment outcome. Based on cumulative incidences in five years, the cancer recurrence is greater in patients with higher level of Survivin.(29)

Telomerase is a ribonucleoprotein that adds a species-dependent telomere repeat sequence to the $3^{\prime}$ end of telomeres. By preventing DNA from shortening with each cell cycle, Telomerase is able to inhibit cellular senescence and apoptosis.(31) Telomerase activity was detected in $96.5 \%$ of cervical tumor samples and in $68.7 \%$ of premalignant cervical scrapings but it was not detected in control hysterectomy samples nor in cervical scrapings of normal healthy control. Therefore the absence of Telomerase activity in cervical scrapes of healthy women indicated the potential of Telomerase as a screening marker for early diagnosis of cervical cancer.(32) Since Cytochrome $\mathrm{C}$, Survivin and Telomerase are important biomarkers for cervical cancers, therefore the present study was conducted to investigate the correlation of these biomarkers with the outcome of radiotherapy in the advanced stage of cervical cancer.

\section{Methods}

\section{Subject Recruitment and Selection}

A prospective study with nested case-control method was conducted to see the role of Survivin, Telomerase and Cytochrome $\mathrm{C}$ as markers of cervical cancer radiotherapy outcomes in addition to clinicopathologic features. The study was conducted in Dr. Cipto Mangunkusumo National Central General Hospital, Jakarta, from January 2016 to May 2017. Subjects were recruited and selected based on the inclusion criteria of having untreated cervical cancer with the extension into the pelvic sidewall, hydronephrosis or non-functioning kidney with histopathologic type of squamous cell carcinoma (stage IIIB according to Fédération Internationale de Gynécologie et d'Obstétrique (FIGO) staging of cervical cancer). Meanwhile the exclusion criteria were subjects diagnosed with Human Immunodeficiency Virus (HIV), severe systemic diseases, heart disease, sclerosis and wound healing. Prior to recruitment and selection, all subjects had agreed to participate in the study and signed the informed consent. The study protocol was approved by the Research Ethics Committee, Faculty of Medicine, Universitas Indonesia (Ethical clearance No. 446/UN2.F1/ ETIK/2015).

\section{Radiotherapy}

Subjects who matched the criteria were evaluated with magnetic resonance imaging (MRI) before starting the radiotherapy. Radiotherapy was done using $3 \mathrm{D}$ conformal radiotherapy. The total dosage were $70 \mathrm{~Gy}$, consist of external radiation for whole pelvis as primary therapy at a dose of 45-50 Gy divided into 1.8-2 Gy each fraction, 5 fraction per week (total 25-28 fractions), followed by Ir192 afterloading high-dose-rate (3x7 Gy) intracaviter brachytherapy. After 2-3 months, the therapy response was re-evaluated with MRI.

Radiotherapy responses were divided into good and poor response. Good response subjects were those who had complete response (no lesion, no new lesion, and no related symptom) or partial response ( $\geq 30 \%$ reduction of lesion size, no new lesion, no progressive disease). Poor response group was further divided into progressive response or no response. The definition of progressive response was $>20 \%$ increase of the lesion size, growth of a new lesion, or the deterioration of the disease. No response subjects were those who could not be qualified as complete, partial, or progressive response. 


\section{Histopathology}

Sections from the resected tumors were prepared and stained with hematoxylin and eosin. The sections were then analyzed by a pathologist to determine the differentiation type (well differentiated, moderately differentiated, poorly differentiated, and undifferentiated), based on The World Health Organization (WHO) classification.

\section{Enzyme-linked Immunosorbent Assay (ELISA) for Survivin, Telomerase and Cytochrome $\mathrm{C}$}

ELISA for Survivin, Telomerase and Cytchrome $\mathrm{C}$ were performed using Human Surv (Survivin) ELISA Kit (Catalog No.: E-EL-H1584, Elabscience, Houston, USA), Human TE (Telomerase) ELISA Kit (Catalog No.: E-EL-H0164, Elabscience) and Human Cyt-C (Cytochrome C) ELISA Kit (Catalog No.: E-EL-H0056, Elabscience). Basically, each micro ELISA plate provided was pre-coated with an antibody specific to human Survivin, Telomerase or Cytochrome C. Standards or the resected tumor samples were added to the micro ELISA plate wells and combined with the specific antibodies. Then an Avidin-Horseradish Peroxidase (HRP)conjugated detection antibody specific for human Survivin, Telomerase or Cytochrome $\mathrm{C}$ was added to each micro plate well and incubated. After washing, the substrate solution was added to each well. Only wells containing human Survivin, Telomerase or Cytochrome C appeared in blue color. The enzyme-substrate reaction was terminated by the addition of stop solution and the color turned yellow. The optical density (OD) was measured spectrophotometrically at a wavelength of $450 \mathrm{~nm} \pm 2 \mathrm{~nm}$. The OD value was proportional to the concentration of human Survivin, Telomerase or Cytochrome C. Concentration of human Survivin, Telomerase or Cytochrome $\mathrm{C}$ in the samples was calculated by comparing the $\mathrm{OD}$ of the samples to the standard curve.

\section{Statistical Analysis}

Collected data were analyzed using SPSS for Macintosh ver. 20 (IBM Corp., Armonk, NY, USA). Bivariate analysis to assess relation of Survivin, Telomerase, and Cytochrome C activity on radiotherapy response was done by determining the value of Survivin, Telomerase, and Cytochrome $\mathrm{C}$ activity limit considered significant using Receiver Operating Characteristic (ROC). Furthermore, bivariate analysis was done to find the correlation between variables using chi-square method. If the requirement of chi-square test was not fulfilled, Fisher test would be done to evaluate the correlation between variables.

\section{Results}

A total of 76 subjects who met the criteria was further analyzed. Subject characteristics are shown in Table 1. Bivariate analyses of relation between subject characteristics and radiotherapy response were performed. There was no significant correlation between radiotherapy response and age $(p=0.07)$, parity $(p=0.22)$, first sexual intercourse age $(p=0.43)$, diameter of tumor $(p=0.32)$ and differentiation type $(p=0.08)$.

Mean levels of Survivin, Telomerase and Cytochrome $\mathrm{C}$ were $632.82 \mathrm{pg} / \mathrm{mL}, 5.59 \mathrm{pg} / \mathrm{mL}$ and $204.75 \mathrm{ng} / \mathrm{mL}$, respectively. Survivin, Telomerase and Cytochrome C levels were categorized using ROC curve analysis. Cut off limit of Survivin was set to $932 \mathrm{pg} / \mathrm{mL}$, considering likelihood ratio (LR)+ value of 2.54 , sensitivity $37.90 \%$, specificity $85.10 \%$, and accuracy of $57.90 \%$ (Figure 1A). Cutoff limit of Telomerase was set to $5.75 \mathrm{pg} / \mathrm{mL}$, considering LR+ value of 2.26 , sensitivity $46.80 \%$, specificity $79.30 \%$, and accuracy of $63.05 \%$ (Figure 1B). Meanwhile, cut off limit of Cytochrome $\mathrm{C}$ was set to $122.92 \mathrm{ng} / \mathrm{mL}$, considering LR+ value of 1.09 , sensitivity $78.70 \%$, specificity $27.60 \%$, and accuracy of $53.15 \%$ (Figure $1 \mathrm{C}$ ).

Based on chi-square analysis, there were significant correlation between radiotherapy response and Survivin $(p=0.041)$ or Telomerase $(p=0.022)$. Relative risk of this study was 1.833 (1.067-3.150, CI 95\%) for Survivin (Table 2) and 2.236 (1.038-4.820, CI 95\%) for Telomerase (Table

Table 1. Subjects characteristics $(n=76)$.

\begin{tabular}{|c|c|}
\hline Characteristics & \\
\hline Mean of age (years old) & 50.29 \\
\hline \multicolumn{2}{|l|}{ First sexual intercourse } \\
\hline$<20$ years old & $33(43.4 \%)$ \\
\hline$\geq 20$ years old & $43(56.6 \%)$ \\
\hline Median of parity & $3(0-8)$ \\
\hline Diameter of tumor $(\mathrm{cm})$ & $5.35(1.9-15.0)$ \\
\hline \multicolumn{2}{|l|}{ Differentiation type* } \\
\hline well and moderately & $19(25.0 \%)$ \\
\hline poor and undifferentiated & $57(75.0 \%)$ \\
\hline \multicolumn{2}{|l|}{ Radiotherapy response } \\
\hline positive & $49(61.8 \%)$ \\
\hline negative & $27(38.2 \%)$ \\
\hline
\end{tabular}


A

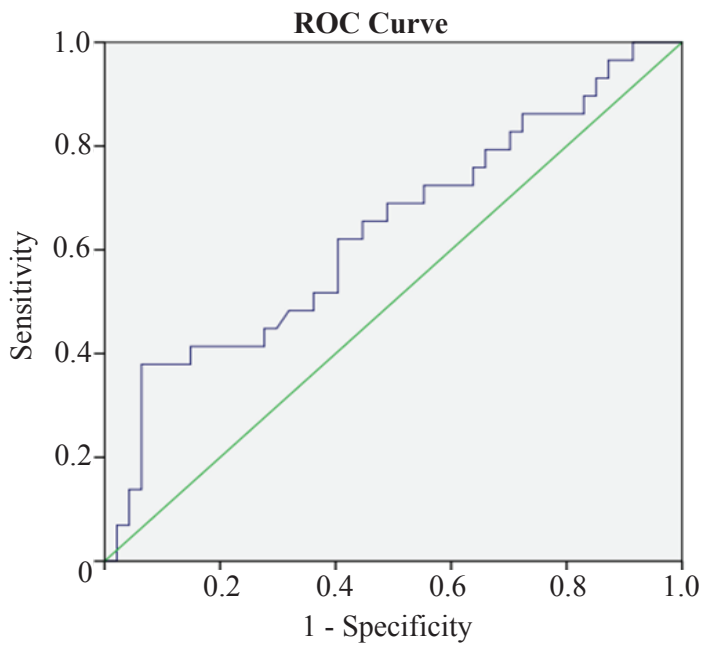

C

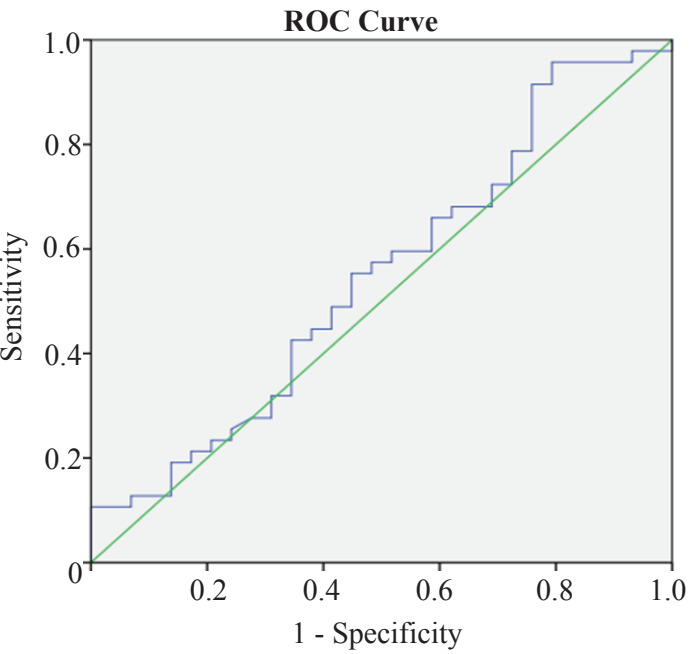

3). However, there was no significant correlation between radiotherapy response and Cytochrome $\mathrm{C}(p=0.530)$.

Kaplan-Meier study was also done in this study to compare the subject survival rate of stage IIIB cervical squamous cell carcinoma with Survivin (Figure 2) and Telomerase (Figure 3). Subjects with lower Survivin level $(<932 \mathrm{pg} / \mathrm{mL})$ had higher 1-year survival rate $(63 \%)$ than subjects with higher Survivin level (50\%). Similar results were obtained for subjects with lower Telomerase level $(<5.75 \mathrm{pg} / \mathrm{mL})$, who had higher 1-year survival rate $(60 \%)$ than subjects with higher Telomerase level (43\%).

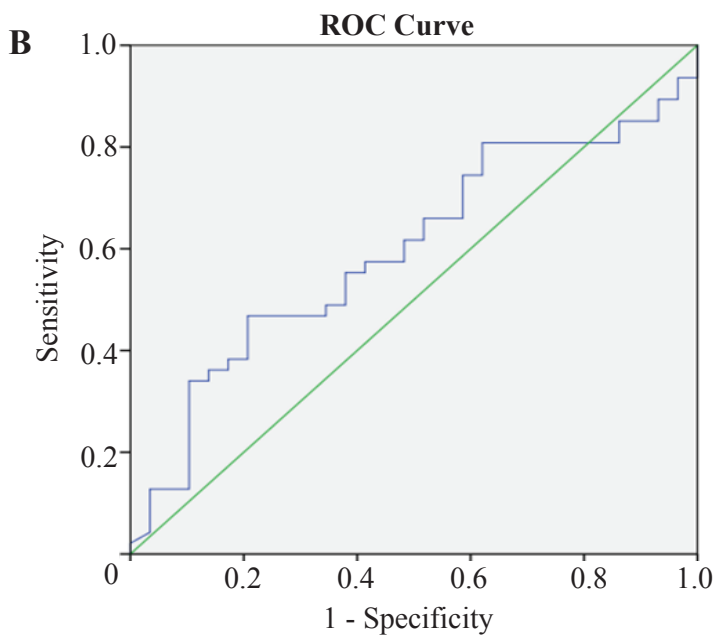

Figure 1. ROC curve of Survivin, Telomerase and Cytochrome C. A: ROC curve of Survivin, B: ROC curve of Telomerase, C: ROC curve of Cytochrome C.

\section{Discussion}

From 2016 to 2017, most of patients with stage IIIB cervical squamous cell carcinoma in Dr. Cipto Mangunkusumo National Central General Hospital were 50 years old and had 3 children. This data is similar to a previously reported study which showed that the risk of having cervical cancer was higher in patients age of 50 years or more with odd ratio of 2.53.(7) However, our results showed no significant correlation between age, first sexual intercourse age, and

Table 2. Bivariate analysis between Survivin level and radiotherapy response.

\begin{tabular}{|c|c|c|c|c|c|}
\hline \multirow{2}{*}{$\begin{array}{l}\text { Survivin Level } \\
\quad(\mathrm{pg} / \mathrm{mL})\end{array}$} & \multicolumn{2}{|c|}{ Response } & \multirow{2}{*}{ Total } & \multirow{2}{*}{$p$-value } & \multirow{2}{*}{ Relative Risk } \\
\hline & Poor & Good & & & \\
\hline$\geq 932$ & $11(57.9 \%)$ & $8(42.1 \%)$ & $19(25.0 \%)$ & \multirow{3}{*}{$0.041^{*}$} & \multirow{3}{*}{$\begin{array}{c}1.833 \\
(1.067-3.150, \text { CI 95\%) }\end{array}$} \\
\hline$<932$ & $18(31.6 \%)$ & $39(68.4 \%)$ & $57(75.0 \%)$ & & \\
\hline Total & $29(38.2 \%)$ & $47(61.8 \%)$ & $76(100.0 \%)$ & & \\
\hline
\end{tabular}

*Tested with chi-square. 
Table 3. Bivariate analysis between Telomerase level and radiotherapy response.

\begin{tabular}{|c|c|c|c|c|c|}
\hline \multirow{2}{*}{$\begin{array}{l}\text { Telomerase Level } \\
(\mathrm{pg} / \mathrm{mL})\end{array}$} & \multicolumn{2}{|c|}{ Response } & \multirow{2}{*}{ Total } & \multirow{2}{*}{$p$-value } & \multirow{2}{*}{ Relative Risk } \\
\hline & Poor & Good & & & \\
\hline$\geq 5.75$ & $23(47.9 \%)$ & $25(52.1 \%)$ & $48(63.2 \%)$ & \multirow{3}{*}{$0.022 *$} & \multirow{3}{*}{$\begin{array}{c}2.236 \\
(1.038-4.820, \text { CI } 95 \%)\end{array}$} \\
\hline$<5.75$ & $6(21.4 \%)$ & $22(78.6 \%)$ & $28(36.8 \%)$ & & \\
\hline Total & $29(38.2 \%)$ & $47(61.8 \%)$ & $76(100.0 \%)$ & & \\
\hline
\end{tabular}

*Tested with chi-square.

parity with radiotherapy outcome in stage IIIB cervical squamous cell carcinoma patients. Previous study also reported no significant correlation in patient age, overall survival, and relapse free survival.(8)

Our results showed that subjects with $\geq 932 \mathrm{pg} /$ $\mathrm{mL}$ Survivin had significant lower 1-year-survival after radiotherapy. This is in accordance with another report that Survivin overexpression is correlated significantly with lower complete remission.(33) Overexpression of Survivin has a poor prognosis and high resistance to therapy. Survivin inhibits both extrinsic and intrinsic apoptotic pathways.(24) Survivin mutants (Thr34-Ala, Ser81Ala, Cys84Ala,) have more potential to inhibit the growth of hepatocellular cancer compared to the use of either one mutant alone.(34-37)

Subjects with high level of Telomerase $(\geq 5.75 \mathrm{pg} / \mathrm{mL})$ had significant poor response to radiotherapy, suggesting

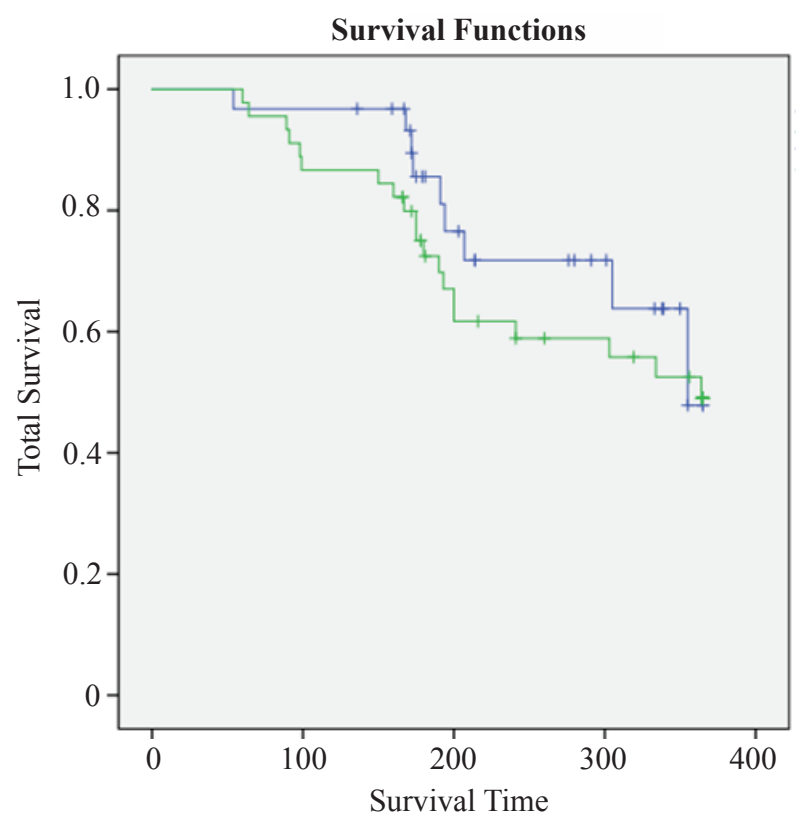

Figure 2. Kaplan Meier graph of 1-year-survival subjects with high and low Survivin level. Blue line: subjects with lower level of Survivin; Green line: subjects with higher level of Survivin. that low level of Telomerase had a better prognosis of radiotherapy responses. Similar studies showed that low level of Telomerase had a better radiotherapy response. Another study reported that Telomerase had roles in tumor development and induction of chromosomal instability, therefore Telomerase activity can serve as a tumor marker. (38) In the contrary, the absence of proliferation was observed in human cells due to lack of Telomerase. Lack of Telomerase will limit tumor cell growth that duplicate continuously. Thus Telomerase inhibitor is a promising factor in eliminating cancer cells.(39)

Level of Cytochrome $\mathrm{C}$ was not correlated significantly with the radiotherapy response and 1-year-survival. Low level of Cytochrome $\mathrm{C}$ in the cytoplasm are assumed due to Cytochrome $\mathrm{C}$ was reserved in the mitochondria and not been released into the cytoplasm. Level of Cytochrome $\mathrm{C}$

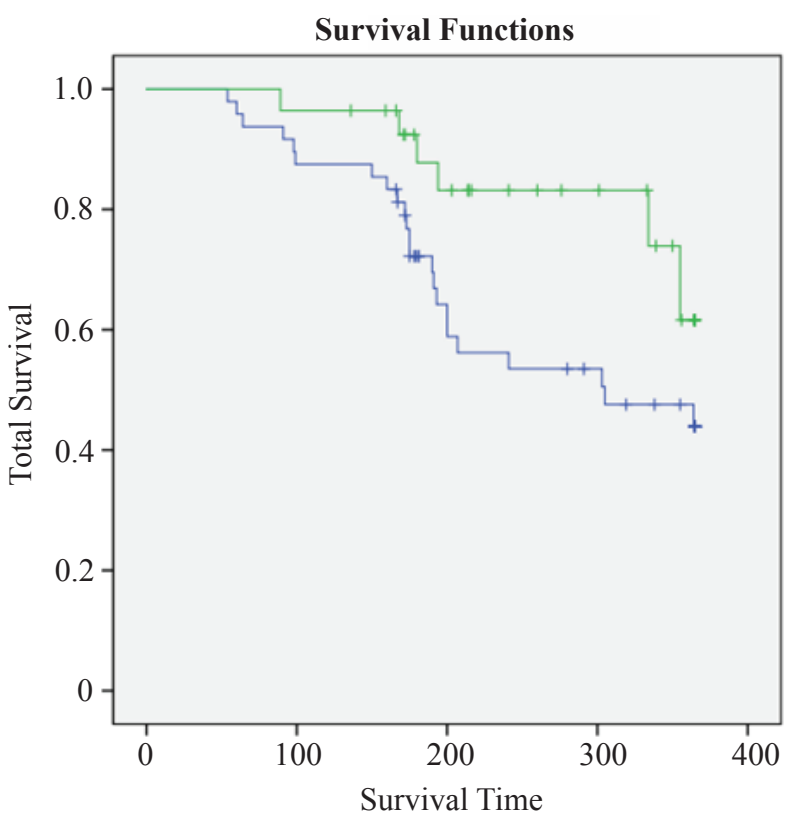

Figure 3. Kaplan Meier graph of 1-year-survival subjects with high and low Telomerase level. Blue line: subjects with higher level of Telomerase; Green line: Subjects with lower level of Telomerase. 
will be increased in the cytoplasm if there is a cell damage. (40) Therefore, level of Cytochrome $\mathrm{C}$ should be further investigated at a correct time point after radiotherapy.

A scoring model to predict the radiotherapy response was calculated based on $\mathrm{Z}$ value of multivariate analysis. The coefficient of variable beta scoring that correlated ( $p$-value $<0.5)$ with the radiotherapy response was coefficient of Survivin: $(2.65 / 3.89) \times 10=6.8$ and coefficient of Telomerase: $(3.89 / 3.89) \times 10=10$. So the scoring model is $6.8 \mathrm{~S}+10 \mathrm{~T}$ with $\mathrm{S}$ for Survivin and $\mathrm{T}$ for Telomerase. The scoring model cut-off point is $\geq 13.4$ to determine the prediction of negative response. This cut-off point has values of LR+2.08, specificity $85.1 \%$, sensitivity $31.0 \%$ and accuracy $58.5 \%$. From the value of LR+ can be calculated the probability value after test is $67.5 \%$. The probability of patients with a predictor score of $\geq 13.4$ had a negative response increased to $67.5 \%$. The predictor score of $\geq 13.4$ is a sufficient diagnostic test to predict a negative response in stage IIIB cervical cancer patients.

\section{Conclusion}

Radiotherapy response is significantly correlated with Survivin and Telomerase levels of subjects with stage IIIB cervical squamous cell carcinoma. In addition, the subjects with lower Survivin or Telomerase level, have higher 1-year survival rate. Taken together, Survivin and Telomerase could be potential predictors of radiotherapeutic response for subjects with stage IIIB cervical squamous cell carcinoma.

\section{References}

1. Lindel K, Burri P, Studer HU, Altermatt HJ, Greiner RH, Gruber G. Human papillomavirus status in advanced cervical cancer: predictive and prognostic significance for curative radiation treatment. Int J Gynecol Cancer. 2005; 15: 278-84.

2. Franco EL, Duarte-Franco E, Ferenczy A. Cervical cancer: epidemiology, prevention and the role of human papillomavirus infection. CMAJ. 2001; 164: 1017-25.

3. Castellsagué X. Natural history and epidemiology of HPV infection and cervical cancer. Gynecol Oncol. 2008; 110: S4-7.

4. Parkin DM. The global health burden of infection-associated cancers in the year 2002. Int J Cancer. 2006; 118: 3030-44.

5. Andrijono. Kanker serviks. 3th Ed. Jakarta: Pustaka Spirit; 2009.

6. Aziz MF. Masalah kanker serviks. Cermin Dunia Kedokteran. 2001; 133: 5-7.

7. Long HJ, Laack NN, Gostout BS. Prevention, diagnosis, and treatment of cervical cancer. Mayo Clin Proc. 2007; 82: 1566-74.

8. Rose PG. Chemoradiotherapy: the new standard care for invasive cervical cancer. Drugs. 2000; 60: 1239-44.
9. Friedlander M, Grogan M, U.S. Preventative Services Task Force. Guidelines for the treatment of recurrent and metastatic cervical cancer. Oncologist. 2002; 7: 342-7.

10. Perez CA, Grigsby PW, Camel HM, Galakatos AE, Mutch D, Lockett MA. Irradiation alone or combined with surgery in stage IB, IIA, and IIB carcinoma of uterine cervix: update of a nonrandomized comparison. Int J Radiat Oncol Biol Phys. 1995; 31: 703-16.

11. Gadducci A, Tana R, Fanucchi A, Genazzani AR. Biochemical prognostic factors and risk of relaps in patients with cervical cancer. Gynecol Oncol. 2007; 107: S23-6.

12. Zusterzeel PL, Span PN, Dijsterhuis MG, Thomas CM, Sweep FC, Massuger LF. Serum vasculer endothelial growth factor: a prognostic factor in cervical cancer. J Cancer Res Clin Oncol. 2009; 135: 283-90.

13. Li K, Li Y, Shelton JM, Richardson JA, Spencer E, Chen ZJ, et al. Cytochrome $\mathrm{c}$ deficiency causes embryonic lethality and attenuates stress-induced apoptosis. Cell. 2000; 101: 389-99.

14. Pan $\mathrm{J}, \mathrm{Xu} \mathrm{G}$, Yeung SC. Cytochrome c release is upstream to activation of caspase- 9 , caspase- 8 , and caspase- 3 in the enhanced apoptosis of anaplastic thyroid cancer cells induced by manumycin and paclitaxel. J Clin Endocrinol Metab. 2001; 86: 4731-40.

15. Lin HI, Lee YJ, Chen BF, Tsai MC, Lu JL, Chou CJ, et al. Involvement of Bcl-2 family, cytochrome c and caspase-3 in induction of apoptosis by beauvericin in human non-small cell lung cancer cells. Cancer Lett. 2005; 230: 248-59.

16. Sun Y, Tang XM, Half E, Kuo MT, Sinicrope FA. Cyclooxygenase-2 overexpression reduces apoptotic susceptibility by inhibiting the cytochrome c-dependent apoptotic pathway in human colon cancer cells. Cancer Res. 2002; 62: 6323-8.

17. Herman-Antosiewicz A, Johnson DE, Singh SV. Sulforaphane causes autophagy to inhibit release of cytochrome $\mathrm{C}$ and apoptosis in human prostate cancer cells. Cancer Res. 2006; 66: 5828-35.

18. Way TD, Kao MC, Lin JK. Degradation of HER2/neu by apigenin induces apoptosis through cytochrome c release and caspase-3 activation in HER2/neuoverexpressing breast cancer cells. FEBS Lett. 2005; 579: 145-52.

19. Arung ET, Wicaksono BD, Handoko YA, Kusuma IW, Shimizu K, Yulia D, et al. Cytotoxic effect of artocarpin on T47D cells. J Nat Med. 2010; 64: 423-9.

20. Sandra F. Targeting Ameloblatoma into Apoptosis. Indones Biomed J. 2018; 10: 35-9.

21. Wolf BB, Schuler M, Li W, Eggers-Sedlet B, Lee W, Tailor P, et al. Defective cytochrome c-dependent caspase activation in ovarian cancer cell lines due to diminished or absent apoptotic protease activating factor-1 activity. J Biol Chem. 2001; 276: 34244-51.

22. Suzuki S, Higuchi M, Proske RJ, Oridate N, Hong WK, Lotan R. Implication of mitochondria-derived reactive oxygen species, cytochrome $\mathrm{C}$ and caspase-3 in N-(4-hydroxyphenyl)retinamideinduced apoptosis in cervical carcinoma cells. Oncogene. 1999; 18: 6380-7.

23. Ferry S, Matsuda M, Yoshida H, Hirata M. Inositol hexakisphosphate blocks tumor cell growth by activating apoptotic machinery as well as by inhibiting the Akt/NFkappaB-mediated cell survival pathway. Carcinogenesis. 2002; 23: 2031-41.

24. Altieri DC. Survivin, versatile modulation of cell division and apoptosis in cancer. Oncogene. 2003; 22: 8581-9.

25. Sandra F, Khosravi-Far R. Ser81 Survivin Induced Protein Kinase A (PKA)-dependent Phosphatidylinositol 3-kinase (PI3K) Activity. Indones Biomed J. 2014; 6: 157-62.

26. O'Driscoll L, Linehan R, Clynes M. Survivin: role in normal cells and in pathological conditions. Curr Cancer Drug. 2003; 3: 131-52.

27. Chakravarti A, Zhai GG, Zhang M, Malhotra R, Latham DE, Delaney 
MA, et al. Survivin enhances radiation resistance in primary human glioblastoma cells via caspase-independent mechanisms. Oncogene. 2004; 23: 7494-506.

28. Kennedy SM, O'Driscoll L, Purcell R, Fitz-simons N, McDermott $\mathrm{EW}$, Hill $\mathrm{AD}$, et al. Prognostic importance of survivin in breast cancer. Br J Cancer. 2003; 88: 1077-83.

29. Rodel F, Hoffmann J, Distel L, Herrmann M, Noisternig T, Papadopoulos T, et al. Survivin as a radioresistance factor, and prognostic and therapeutic target for radiotherapy in rectal cancer. Cancer Res. 2005; 65: 4881-7.

30. Smith SD, Wheeler MA, Plescia J, Colberg JW, Weiss RM, Altieri DC. Urine detection of survivin and diagnosis of bladder cancer. JAMA. 2001; 285: 324-8.

31. Reddy VG, Khanna N, Jain SK, Das BC, Singh N. Telomerase-A molecular marker for cervical cancer screening. Int J Gynecol Cancer. 2001; 11: 100-6.

32. Philippi C, Loretz B, Schaefer UF, Lehr CM. Telomerase as an emerging target to fight cancer: opportunities and challenges for nanomedicine. J Control Release. 2010; 146: 228-40.

33. Zaffaroni N, Pennati M, Colella G, Perego P, Supino R, Gatti L, et al. Expression of the anti-apoptotic gene survivin correlates with taxol resistance in human ovarian cancer. Cell Mol Life Sci. 2002; 59: 1406-12.

34. Zhang R, Wang T, Li KN, Qin WW, Chen R, Wang K, et al. A survivin double point mutant has potent inhibitory effect on the growth of hepatocellular cancer cells. Cancer Biol Ther. 2008; 7: 547-54.

35. Sandra F, Khosravi-Far R. Survivin S81A Enhanced TRAIL's Activity in Inducing Apoptosis. Indones Biomed J. 2010; 2: 113-7.

36. Sandra F, Khosravi-Far R. Phosphorylated-Survivin at Ser81 Induced Protein Kinase A (PKA): A Back Loop. Indones Biomed J. 2011; 3 : $138-42$.

37. Sandra F. Survivin Ser81 Plays an Important Role in PI3K/Akt/ mTOR Signaling Pathway. Mol Cell Biomed Sci. 2018; 2: 55-9.

38. González-Suárez E, Samper E, Flores JM, Blasco MA. Telomerasedeficient mice with short telomeres are resistant to skin tumorigenesis. Nat Genet. 2000; 26: 114-7.

39. Holysz H, Lipinska N, Paszel-Jaworska A, Rubis B. Telomerase as a useful target in cancer fighting the breast cancer case. Tumour Biol. 2013; 34: 1371-80.

40. Eleftheriadis T, Pissas G, Liakopoulos V, Stefanidis I. Cytochrome c as a potentially clinical useful marker of mitochondrial and cellular damage. Front Immunol. 2016; 7: 279. 